\title{
Spontaneous recovery in phacolytic glaucoma
}

\author{
Pierre Blaise, MD, Bernard Duchesne, MD, PhD, Serge Guillaume, MD, Albert Galand, MD, PhD
}

We report a case of phacolytic glaucoma in which spontaneous absorption of the hypermature lens allowed a patient who refused surgery to recover a normal pressure and satisfactory visual acuity.

J Cataract Refract Surg 2005; 31:1829-1830 @ 2005 ASCRS and ESCRS

Cataract extraction is considered to be the definitive treatment and the only possibility for recovery from phacolytic glaucoma. ${ }^{1,2}$ We report a case of phacolytic glaucoma managed by topical medications with rapid recovery of normal pressure and satisfactory visual acuity.

\section{CASE REPORT}

A 79-year-old woman was referred to our department with a 3-day history of unbearable pain in her left eye. This eye was nonfunctional because of the gradual development of a senile cataract noted more than 5 years prior to admission and for which she had refused to have surgery.

Best corrected visual acuity was 4/10 in the right eye and very mild light perception without projection in the left eye. Slitlamp examination showed a nuclear cataract in the right eye, while the left eye presented diffuse corneal edema, intense flare with iridescent particles in the anterior chamber, and a totally opacified white cataract. The anterior chamber angle was open, and no keratic precipitates were present. The diagnosis of phacolytic glaucoma was confirmed by applanation tonometry, intraocular pressures (IOPs) being $20 \mathrm{~mm} \mathrm{Hg}$ and $62 \mathrm{~mm} \mathrm{Hg}$ in the right and left eyes, respectively. Treatment was initiated topically with atropine and dexamethasone 3 times a day and timolol $0.5 \%$ twice a day and orally with acetazolamide $500 \mathrm{mg}$ a day.

Despite rapid pain relief, IOP in the left eye did not decrease to below $50 \mathrm{~mm} \mathrm{Hg}$. However, because the patient was now pain free, she still categorically refused surgery and went home with topical medication alone, acetazolamide orally having been changed to dorzolamide twice a day. Seven months later, the patient came back after missing previous appointments and spontaneously stopping her treatment. She reported a marked improvement of vision in her left eye. Examination revealed an unexpected absorption of lens material with disappearance of the flare and a capsular bag containing only a thin white opacity

Accepted for publication February 18, 2005.

From the Department of Ophthalmology, Centre Hospitalier Universitaire Sart Tilman, University of Liège, Liège, Belgium.

No author has a financial or proprietary interest in any material or method mentioned.

Reprint requests to Pierre Blaise, MD, Department of Ophthalmology, CHU Sart Tilman, University of Liège, B-4000 Liège, Belgium.
(Figure 1). In parallel, visual acuity increased to $5 / 10$ with +12 diopters while IOP had fallen to $20 \mathrm{~mm} \mathrm{Hg}$.

\section{DISCUSSION}

Phacolytic glaucoma is a lens-induced open-angle glaucoma in which a mature or hypermature cataract leaks its soluble contents into the anterior chamber. In contrast to lens particle glaucoma, where obvious lens fragments circulate in the aqueous humor after gross capsule disruption, phacolytic glaucoma occurs with a macroscopically intact capsule. ${ }^{1}$ Over time, the aqueous humor becomes saturated with formation of calcium oxalate and cholesterol crystals that appear as iridescent particules. At the same time, the blockage of the trabecular meshwork by heavy molecular weight proteins from the lens, as well as by swollen macrophages, leads to a characteristically severe rise of IOP. ${ }^{1,3}$

Intracapsular or the currently preferred extracapsular cataract extraction has been shown to be effective both in controlling the IOP and restoring vision in phacolytic glaucoma. Presurgical management is essential to lowering the IOP using topical $\beta$-blockers and topical or systemic carbonic anhydrase inhibitors and to reduce inflammation with topical cycloplegics and steroids. ${ }^{1,2}$ Even if visual acuity in phacolytic glaucoma is often worse than hand motion, good vision can be obtained after cataract extraction. However, despite its efficacy, such surgery is not always possible either because of the general health of the patient or because of patient refusal, as in this case.

Few cases of spontaneous cataract absorption have been reported at the beginning of the last century, but generally with a negative outcome, vision being lost because of glaucoma. ${ }^{4}$ Absorption of lens material is not common and is currently only described in children or in specific situations such as uveitis, congenital dysgenesis, or trauma. ${ }^{5}$ Absorption of cataract is considered spontaneous only if no adequate explanation is apparent. Therefore, the diagnosis of spontaneous absorption must involve a careful review of the patient's medical record for possible causes such 


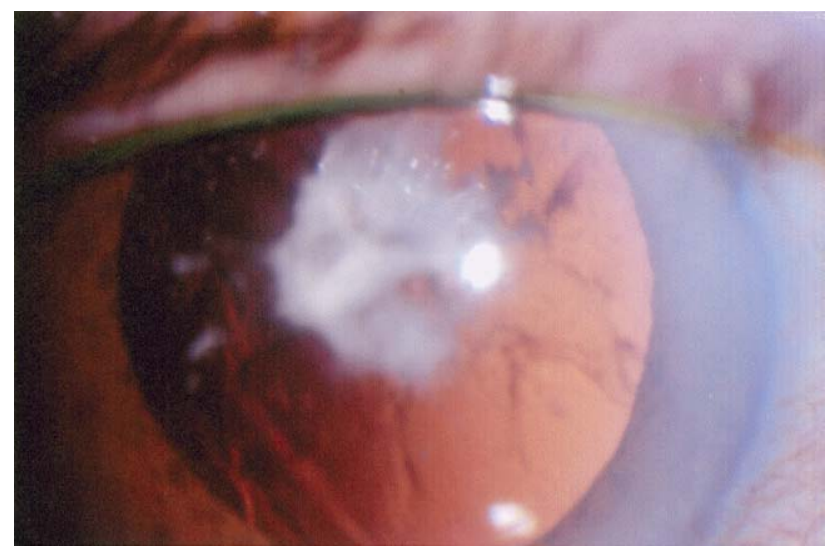

Figure 1. Spontaneous absorption of lens material with a capsular bag containing only a thin white opacity.

as rubella, uveitis, or trauma. Careful examination of the capsule and ophthalmoscopy in full mydriasis are also essential; dislocation or subluxation of the lens and drop of the nucleus into the vitreous must be excluded. ${ }^{6}$

In our patient, medical history and the capsular bag integrity argued for spontaneous cataract absorption. The role of topical treatment, specifically the antiinflammatory drops, in almost complete absorption of the lens cannot be affirmed. Contrary to the situation at the beginning of the last century, drugs such as timolol and acetazolamide are currently available and enabled the maintenance of a reasonable IOP in the course of phacolysis. Because the patient's pain was relieved, she refused cataract extraction. Acetazolamide was also stopped because of fear of inducing electrolyte disturbances in this noncompliant patient. In hindsight, more aggressive treatment would have been useful to attain a further decrease of IOP and better preserve visual field.

In conclusion, cataract extraction is the best way to manage phacolytic glaucoma. When surgery is not possible, medical treatment remains indispensable. Its aim must be to not only abolish pain but also to reduce IOP as low as possible to preserve visual function in case of eventual spontaneous lens absorption.

\section{REFERENCES}

1. Epstein DL. Diagnosis and management of lens-induced glaucoma. Ophthalmology 1982; 89:227-230

2. Mandal AK. An alternate way to manage patients with Morgagnian cataracts and phacolytic glaucoma. Indian J Ophthalmol 1997; 45:53-59

3. Richter CU. Lens-induced open-angle glaucoma. In: Ritch R, Shields MB, Krupin T, eds, The glaucomas, $2 d$ ed. St Louis, MO, CV Mosby, 1996; Vol. 2:1023-1031

4. Gifford $\mathrm{H}$. The danger of the spontaneous cure of senile cataract. Am J Ophthalmol (old series) 1900; 17:289-293

5. Mohan M, Bartholomew RS. Spontaneous absorption of a cataractous lens. Acta Ophthalmol Scand 1999; 77:476-477

6. Marlow SB. Spontaneous absorption of cataract. Trans Am Ophthalmol Soc 1952; 50:283-291; discussion, 291-293 